\title{
Barium granuloma in peritoneal cavity and right scrotal sac mimicking a germ cell tumor
}

Supika Kritsaneepaiboon, M.D.

Surasak Sangkhathat, M.D.

Kanet Kanjanapradit, M.D.

From The Department of Radiology, Faculty of Medicine, Prince of Songkla University, Songkhla, Thailand

Address correspondence to S.K. (e-mail: supikak@yahoo.com)

\section{Abstract}

Colonic perforation after barium enema is rare. We present a case of a 6-month-old boy with a palpable mass at the left sided abdomen and the right sided scrotum. Ultrasound and computed tomography (CT) showed calcified masses at $\mathrm{Cul} \mathrm{de} \mathrm{sac} \mathrm{and} \mathrm{right} \mathrm{scrotum} \mathrm{with} \mathrm{intraperitoneal} \mathrm{fat} \mathrm{infiltration}$ mimicking germ cell tumor. Preexisting colonic wall injury or trauma and exposed to barium enema procedure can help to correct diagnosis and obviate unnecessary surgery.

\section{Introduction}

Barium enema is a safe diagnostic procedure to detect colonic lesions. Although on rare occasions, colonic perforation may transpire. Not only excessive intraluminal pressure, but usually also preexisting weakened colonic wall by iatrogenic trauma or colonic disease can break the colonic wall. Completely disrupted colonic wall produces intra/ extraperitoneal perforation which is clinically more severe. When barium perforation occurs, granulomatous reaction around barium forms the so called "barium (sulfate) granuloma". We present a case of barium granuloma occurring after colonic biopsy and mimicking germ cell tumor. 


\section{Case Summary}

A 6-month-old infant was presented with palpable mass at the left sided abdomen and the right scrotum. Ultrasound and CT showed circumferential calcification along the descending colonic wall with intraperitoneal fat infiltration, and calcified masses at $\mathrm{Cul}$ de sac and right scrotum (Fig. 1a, 1b, Fig. 2a, 2b). Alpha-fetoprotein was normal based on the patient's age $(93 \mathrm{ng} / \mathrm{ml})$. Germ cell tumor was presumptively diagnosed. Subsequently exploration of laparotomy found colonic fistula at splenic flexure with chronic thick walled abscess connecting through umbilicus. Histology of abscess wall and the right scrotum demonstrated fibrosis, granulation tissue, dystrophic calcification and granulomatous formation (Fig. 3a, 3b). Retrospective review of medical history discovered that colonic biopsy was done at the first day of life because of clinical gut obstruction and the patient underwent ileostomy. Then barium enema was performed at the age of 3 months evaluated before ileostomy closure. Barium granuloma within the peritoneal cavity and the right scrotum via patent processus vaginalis was finally diagnosed.
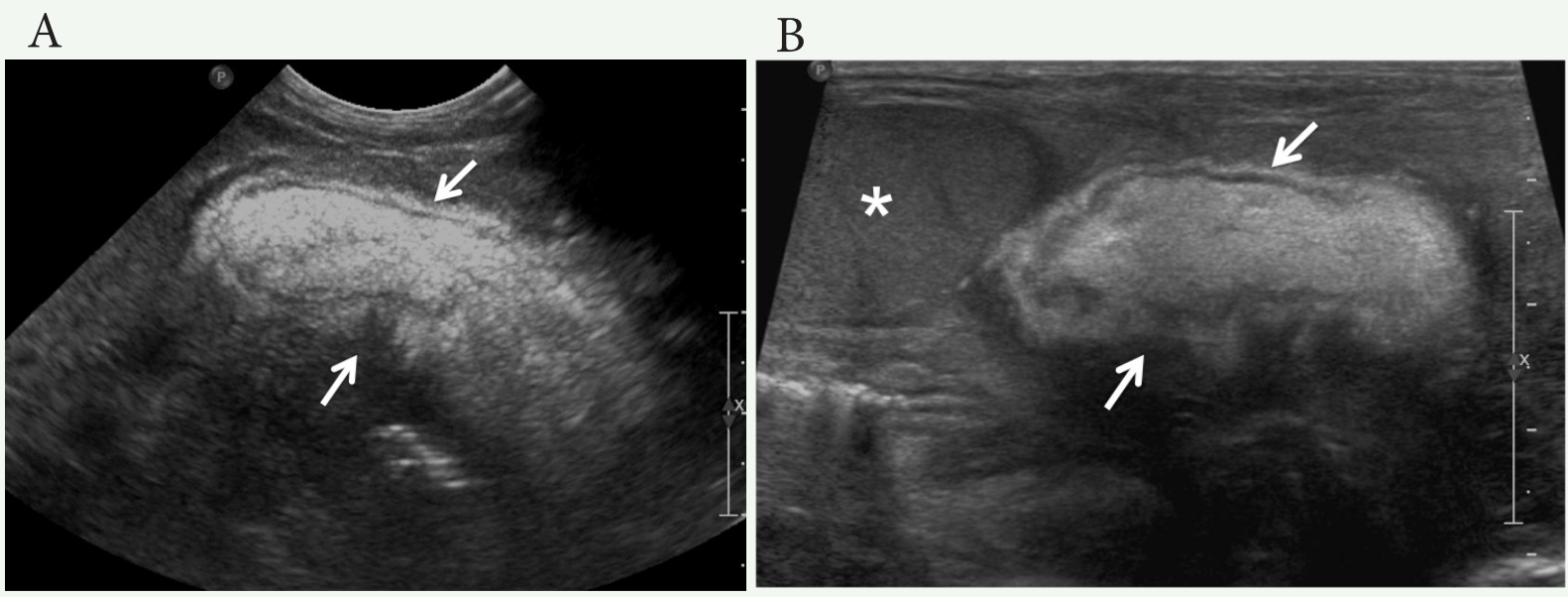

Figure 1. (A) Ultrasound at left sided abdomen shows hyperechoic mass - like lesion (arrows). (B) Ultrasound at the right scrotal sac demonstrates a normal right testis $\left(^{*}\right)$ which is superiorly displaced by a hyperechoic mass like lesion (arrows) with the same characteristics as the lesion in the left sided abdomen. 
A

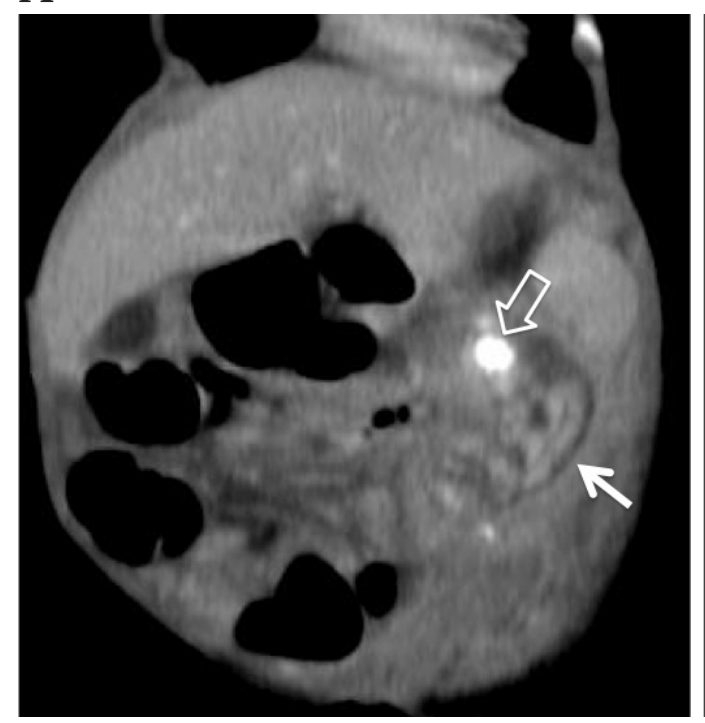

$\mathrm{B}$

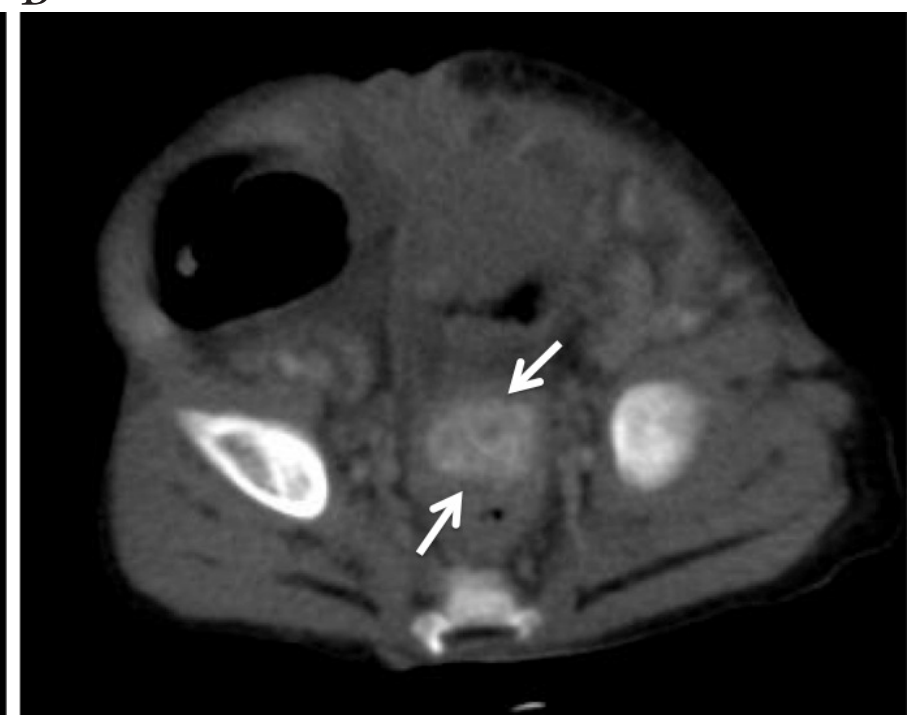

Figure 2. (A) Coronal multiplanar reconstruction image of enhanced CT reveals a dense calcification (open arrow) at splenic flexure and dense calcified wall along descending colon (arrow) with surrounding fat infiltration. (в)Axial enhanced CT at pelvis shows a calcified mass (arrow) at Cul de sac between the urinary bladder and the rectum.

A

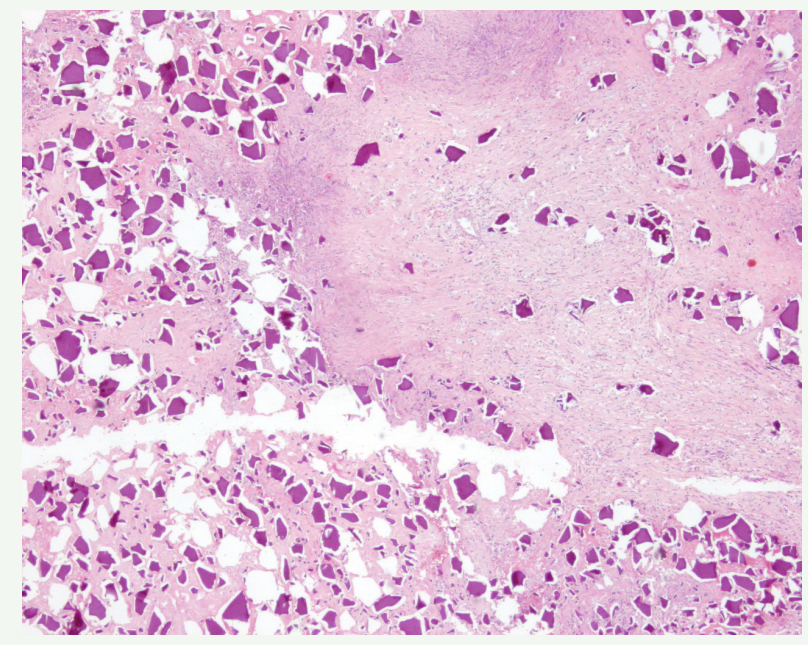

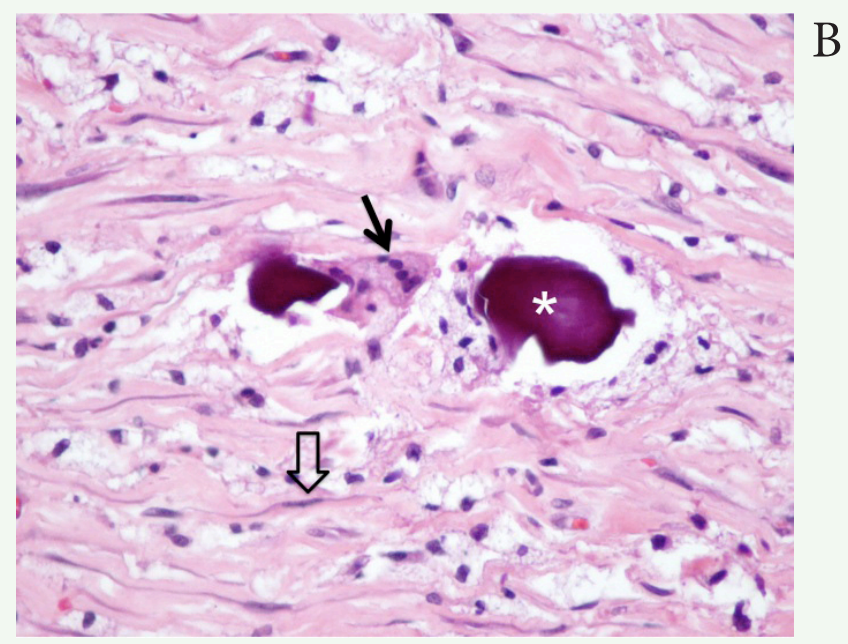

Figure 3. (A) Histological slide shows diffuse calcification with fibrosis and foreign body granuloma. (H\&E) (в) High magnification shows dystrophic calcify $\left(^{*}\right)$ with foreign body type giant cell (arrow) with fibroblastic cell proliferation (open arrow). 


\section{Discussion}

Barium sulfate granuloma is a rare complication after barium contrast study. It was first described in 1954 as a pedunculated rectal mass [1, 2]. Most of the previous reported cases had a history of barium enema. A recent reported case by Kim et al, however, diagnosed a barium granuloma of the rectum in a patient with no history of barium enema but the patient underwent upper gastrointestinal series and colonoscopy was performed nine months later [1]. Colonic perforation after barium enema can occur at any level from dentate line up to cecum and it can be complete entire thickness of colonic wall or incomplete with intact colonic serosa [3,4]. Incomplete dissection of barium can either fill intestinal glands, so called "peculation" which is of no clinical significance or penetrate intramural deposition that may be asymptomatic or develop pain and tenderness in minutes or hours later $[5,6]$. It is usually seen in a post evacuation film and has to be differentiated from true pathologic colitis [5]. If the barium is trapped in the submucosa and lamina propria and localized in the anastomotic site, it can cause fibrosis and anastomotic stricture [7]. A pre-existing disease of the colon or an underlying disease of the patient has increased risk for colonic perforation than those with normal intestines. The previous rectal biopsy, the recent colonic operation, bowel wall diseases: - such as ulcerative colitis, diverticulitis, carcinoma, and parasite manifestation - or rare excessive intraluminal pressure, infants or debilitated patients are also the predisposing factors [2-4].

Barium within peritoneal cavity can create severe inflammatory reaction encountering fibroblasts, multinucleated cells, macrophages and lymphocytes which are the characteristics of a granulomatous reaction surrounding the barium sulfate crystal $[1,8]$. Later on, it can produce a fibrotic change resulting in colonic stricture or intraperitoneal adhesion/fibrosis. Furthermore, intraperitoneal colonic perforation has more serious complications than extraperitoneal perforation or below pouch of Douglas. Sometimes the barium granuloma can mimic a tumorous mass and give incorrect presumptive diagnosis. Kim et al reported a barium granuloma of the rectum whose preoperative diagnosis was calcified submucosal tumor such as gastrointestinal stromal tumor [1]. Our case had the previous colonic biopsy at splenic flexure and then the patient developed a post-operative intra-abdominal collection that were the predisposing factors for colonic 
perforation during barium enema procedure. The barium leaked along the fistulous tract at the biopsy site into the peritoneal cavity and extended to the right scrotum via patent processus vaginalis. This misled the diagnosis of a germ cell tumor in the scrotum with intraabdominal nodal metastasis.

\section{References}

1. Kim DJ, Kim SH, Jeoung AY, Lee KH, Choi BI, Han JK. Barium granuloma of the rectum: case report. J Korean Radiol Soc 2003; 49:43-5.

2. McKee PH, Cameron $\mathrm{CH}$. Barium granuloma of the transverse colon. Postgrad Med J 1978; 54:698-702.

3. Herrington JL Jr. Barium granuloma within the peritoneal cavity: ureteral obstruction 7 years after barium enema and colonic perforation. Ann Surg 1966; 164:162-6.

4. Williams SM, Harned RK. Recognition and prevention of barium enema complications. Curr Probl Diagn Radiol 1991; 20:123-51.

5. Dassel PM. Innocuous filling of the intestinal glands of the colon during barium enema (spiculation) simulating organic disease. Radiology 1962; 78:799-801.

6. Seaman WB, Bragg DG. Colonic intramural barium: a complication of the barium-enema examination. Radiology 1967; 89:250-55.

7. Kitajima T, Tomizawa K, Hanaoka Y, Toda S, Matoba S, Kuroyanagi H, et al. Anastomotic stenosis of the descending colon caused by barium granuloma formation following barium peritonitis: report of a case. Surg Today 2014; 44:2153-6.

8. Levy AD, Shaw JC, Sobin LH. Secondary tumors and tumorlike lesions of the peritoneal cavity: imaging features with pathologic correlation. Radiographics 2009; 29:347-73. 